Journal of Bangladesh Chemical Society, Vol. 24(2), 173-184, 2011.

DOI: $10.3329 /$ jbcs.v24i2.9706

\title{
KINETICS OF THE ALKALINE HYDROLYSIS OF CRYSTAL VIOLET IN MICELLES, REVERSE MICELLES AND MICROEMULSIONS OF CETYLTRIMETHYLAMMONIUM BROMIDE
}

\author{
FERDOUSI BEGUM ${ }^{a}$, MD. YOUSUF A. MOLLAH ${ }^{a}$, M. MUHIBUR RAHMAN ${ }^{a, b}$ AND MD. \\ ABU BIN HASAN SUSAN ${ }^{a *}$ \\ ${ }^{a}$ Department of Chemistry, University of Dhaka, Dhaka-1000, Bangladesh \\ ${ }^{b}$ University Grants Commission of Bangladesh, Agargaon, Dhaka-1207, Bangladesh
}

\begin{abstract}
Kinetics of the alkaline hydrolysis of crystal violet (CV) in micelles, reverse micelles and microemulsions of a cationic surfactant, cetyltrimethylammonium bromide (CTAB) was studied at $25 \pm 0.1{ }^{\circ} \mathrm{C}$ using spectrophotometric method. The rate of alkaline hydrolysis of $\mathrm{CV}$ was catalyzed by micellar solutions of CTAB. The pseudo first order rate constant $\left(k^{\prime}\right)$ has been found to decrease upon incorporation of 1butanol to cationic $\mathrm{CTAB}$ micelles, which displaces the substrate from the micellar into the aqueous phase. In CTAB/cyclohexane/1-butanol/water system, as the content of 1-butanol increases, specific conductivity and density of the microemulsions and reverse micelles decrease. The change in physical properties also causes change in reaction environment. A change from a micelle-rich $(\mathrm{o} / \mathrm{w})$ to a reverse micelle-rich (w/o) condition is apparent for microemulsions and consequently the $k^{\prime}$ vs. \% wt. of 1-butanol profiles show an initial decrease in the $k^{\prime}$ followed by a gradual increase and finally, to a sharp increase with increasing 1butanol content. Microemulsions and reverse micelles thus offer the potential to control rate of a reaction by formation of micelles in water phase and reverse micelles in oil phase.
\end{abstract}

\section{Introduction}

The catalysis of reactions by micelles, reverse micelles and microemulsions has a long and productive history because of its importance in chemical, industrial, pharmaceutical, environmental as well as biological fields ${ }^{1,2}$. With a proper choice of surfactant and a medium, the rate of a reaction can be enhanced 5-10 5 -fold compared to the same reaction in the absence of a surfactant. This resulted in an upsurge of interest to unveil the mechanism of catalysis in such surfactant-based organized media through studies on some model reactions.

Numerous attempts have been made to investigate the catalysis of reactions by micelles, reverse micelles, and microemulsions using a wide variety of substrates, which inter alia, include: esters ${ }^{3,4}, \operatorname{drugs}^{3,5-8}$, and some carbocationic dyes ${ }^{9-16}$. The most widely used substrate has been a triphenylmethane dye, crystal violet (CV) due to its high solubility both in aqueous and organic phase and reversibility of the alkaline hydrolysis of the dye to yield colorless carbinol with high value of equilibrium constant. The rate of the

*Author for correspondence; email: susan@univdhaka.edu 
alkaline fading of $\mathrm{CV}$ has been reported to be greatly accelerated by the addition of cationic surfactants ${ }^{11,14}$ and retarded by anionic surfactants ${ }^{10,11,15,16}$. The addition of some additives in micelles such as, a polymer ${ }^{17}$, cyclodextrins $^{18}$ and counterions ${ }^{2,9}$ in $\mathrm{CTAB}$ micelles produced inhibitory effect on the rate of the alkaline fading of $\mathrm{CV}$.

Micellization behavior changes with concentration and kind of alcohol and consequently reverse micelles also influence chemical reactivity. For instance, 1-hexanol, 1-octanol incorporation into CTAB micelles inhibits the basic hydrolysis of $\mathrm{CV}^{19}$. The reaction has been considerably studied in the medium of anionic, nonionic, and cationic reverse micelles $9,11,20-28$. Physical properties of such systems can be tuned by changing the composition and nature of surfactants and have the potential to control their behavior as a reaction medium.

Microemulsions can solubilize a wide variety of compounds simultaneously and offer the possibility of reagent compartmentalization. These have proved to be very versatile reaction media that induce drastic changes in the reagent concentrations and thus can be specifically used for tuning the reaction rates ${ }^{1}$. The uses of microemulsions as media for a large number of reactions including: nucleophilic substitution reactions ${ }^{29-33}$, enzymatic reactions $^{34,35}$ and hydrolysis reactions ${ }^{36-40}$ are well-known. The reaction rate of alkaline hydrolysis of CV was reported in aerosol-T (AOT)/isooctane/water ${ }^{38}$ and water/AOT/ndecane microemulsions ${ }^{39}$. The alkaline hydrolysis of $\mathrm{CV}$ has beenalso studied in w/o microemulsions of the CTAB/alkanols/cyclohexane system where the reaction has been considered to occur in the water phase of the droplets ${ }^{40}$.

Despite numerous studies, the mechanism of catalysis of the alkaline hydrolysis of CV by micelles, reverse micelles and microemulsions has not yet been well established. In this study, an attempt has been made to make a comprehensive investigation of the kinetics of the alkaline hydrolysis of CV in micelles, reverse micelles and microemulsions of CTAB. The kinetic results in microemulsions have been compared and contrasted with those in reverse micelles and micelles of CTAB. The fundamental physical properties of the reverse micelles and microemuslions have been studied with change in composition and correlated with the kinetic behavior of the hydrolysis of CV in the CTAB/cyclohexane/1butanol/water system. The ultimate goal has been to understand the mechanism of catalysis by w/o or o/w microemulsions, micelles and reverse micelles of CTAB under different reaction environment.

\section{Experimental}

\section{Materials and methods}

Crystal violet (BDH), 1-butanol (Merck), cyclohexane (Merck) and $\mathrm{NaOH}$ were used without further purifications. The cetyltrimethylammonium bromide (BDH) was purified by extraction with ether several times and recrystallized three times from acetone-ethanol (85:15) mixture using the method reported in the literature ${ }^{41}$. 


\section{Preparation of microemulsions and reverse micelles}

The CTAB/1-butanol/cyclohexane/water microemulsions were prepared at fixed CTAB (20\% wt.) and cyclohexane ( 0 and $3.4 \%$ wt.) with different water and 1-butanol contents that ranged from high water to high alcohol content. De-ionized double distilled water with specific conductivity $<0.5 \times 10^{-6} \mathrm{Scm}^{-1}$ at $25^{\circ} \mathrm{C}$ was used for this purpose.

Specific conductances of different microemulsions and reverse micelles were measured with a TOA CM-5S conductimeter, equipped with a dip-type pre-calibrated cell. The specific conductance could be directly measured using the cell constant of the given cell.

Densities of different microemulsions and reverse micelles were measured with a picnometer. The density was calculated by measuring the mass of the solution and picnometer reading.

Kinetic measurements and spectral analysis were carried out in a double beam Shimadzu UV visible spectrophotometer (model UV-160A), equipped with a thermo-regulated cell compartment (temperature control over $\pm 0.1{ }^{\circ} \mathrm{C}$ ) and spectral data processing facilities. Rectangular quartz cells of path length $1 \mathrm{~cm}$ were used throughout the investigation.

\section{Alkaline hydrolysis of $\mathrm{CV}$}

The progress of the alkaline hydrolysis reaction as a function of time was measured spectrophotometrically by monitoring the absorbance due to $\mathrm{CV}^{+}$at its $\lambda_{\max }=592 \mathrm{~nm}(\varepsilon=$ $93587 \times 10^{3} \mathrm{~mol}^{-1} \mathrm{~cm}^{2}$ ). In order to make correction for the scattering of light by the microemulsions and reverse micelles; the absorbance was adjusted to zero before the addition of $\mathrm{CV}$. Aqueous solutions of $\mathrm{CV}$ and different CTAB/1butanol/cyclohexane/water microemulsions and $\mathrm{CTAB} / 1$-butanol/water reverse micelles solutions were mixed in required proportions and the mixtures were allowed to stand for few minutes. Freshly prepared and standardized $\mathrm{NaOH}$ solution was then added to the mixture for kinetic studies maintaining $[\mathrm{NaOH}] \gg\left[\mathrm{CV}^{+}\right]$to keep the pseudo first order condition. The first measurement of absorbance after addition of $\mathrm{NaOH}$ was in between 20-60 seconds after mixing. The temperature was maintained $25 \pm 0.1{ }^{\circ} \mathrm{C}$ in all cases.

\section{Results and discussions}

\section{Critical micelle concentration (CMC) of CTAB in aqueous solution}

The variation in specific conductivity with change in concentrations of aqueous solutions of CTAB was measured to determine the CMC of CTAB. The experimental specific conductance values of $\mathrm{CTAB}$ lie on two straight lines and their point of intersection gave the $\mathrm{CMC}$ value for $\mathrm{CTAB}$ in aqueous solutions. The $\mathrm{CMC}$ value at $25^{\circ} \mathrm{C}$ has been found to have a value of $8.75 \times 10^{-4} \mathrm{M}$ for CTAB aqueous solutions, which is in good agreement with literature data ${ }^{11}$. 


\section{Absorption spectra of $C V$ in different media}

Fig. 1 shows spectra of $3.67 \times 10^{-4} \mathrm{M} \mathrm{CV}$ in aqueous solution, 1-butanol, micelles $(20 \%$ wt. of $\mathrm{CTAB} /$ water) and reverse micelles (20\% wt. of CTAB/1-butanol). The visible absorption spectrum of $\mathrm{CV}$ in aqueous solution shows a prominent peak at $584 \mathrm{~nm}$ with a shoulder at $533 \mathrm{~nm}$ in agreement with Datta et $a l^{11}$. The band at $584 \mathrm{~nm}$ corresponds to the symmetrical helical isomer (A) while at $533 \mathrm{~nm}$ is due to the distorted one (B) ${ }^{42}$. Upon addition of CTAB, the position of the $\lambda_{\max }$ shifted towards higher wavelength to $592 \mathrm{~nm}$ (A) with the shoulder at $541 \mathrm{~nm}$ (B). In 1-butanol and CTAB/ 1-butanol solution, the dielectric constant value is smaller and the A band had only a slight shift and the shoulder (B band) becomes less marked. The equilibrium between two isomers of the carbocation depends on the dielectric constant of the solvents in agreement with literature ${ }^{42}$.

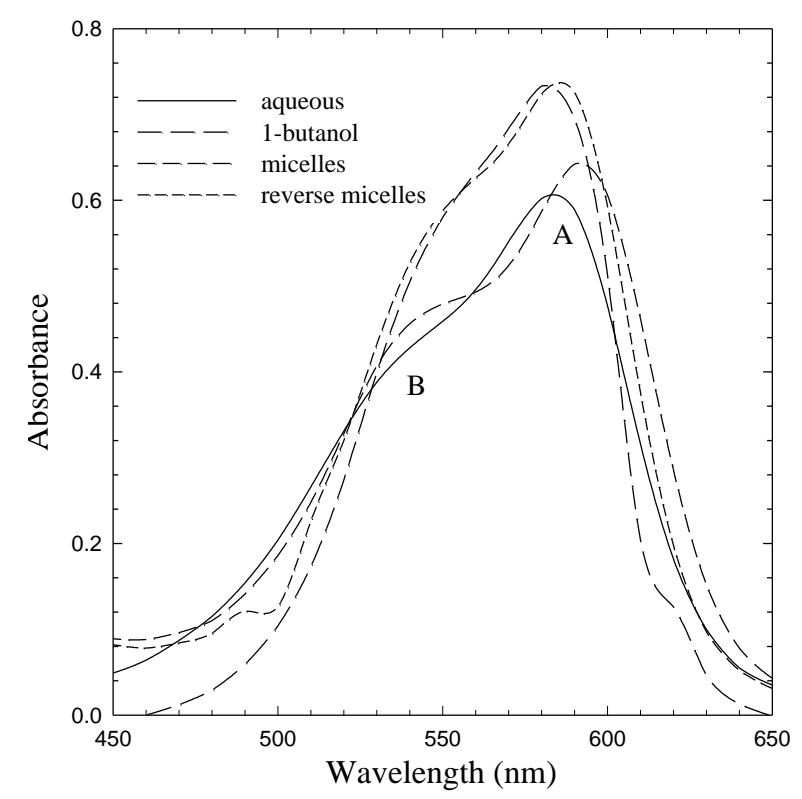

Fig. 1. Spectra of $3.67 \times 10^{-4} \mathrm{M} \mathrm{CV}$ in aqueous solution, 1-butanol, micelles (20\% wt. of CTAB/ water) and reverse micelles ( $20 \%$ wt. of CTAB/1-butanol).

Fig. 2 shows the spectra of $3.67 \times 10^{-4} \mathrm{M} \mathrm{CV}$ solutions in different microemulsions of $\mathrm{CTAB} /$ cyclohexane/1-butanol/water system and reverse micelles of CTAB/1butanol/water system. As the content of 1-butanol increases, the A band shifted slightly to lower wavelength and the shoulder (B band) nearly disappeared indicating a change in the dielectric constant of the medium. 

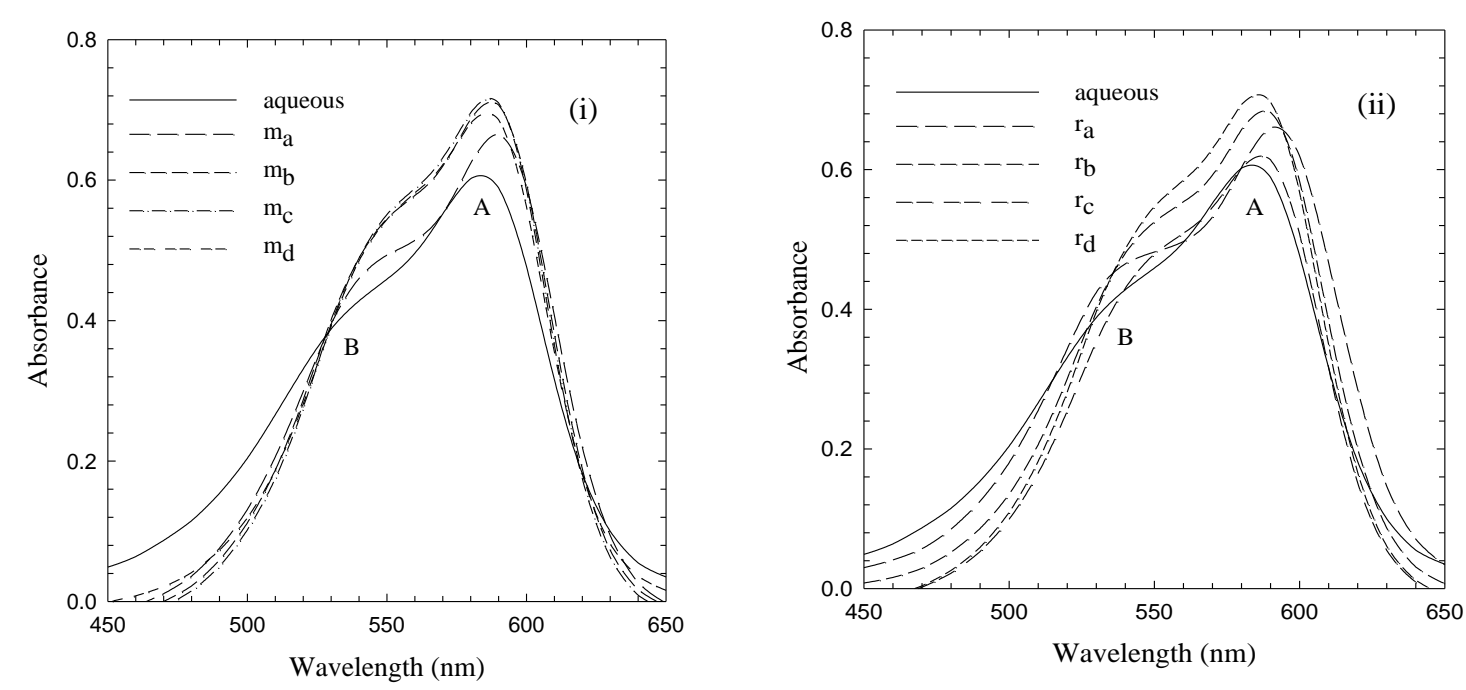

Fig. 2. Spectra of $3.67 \times 10^{-4} \mathrm{M} \mathrm{CV}$ in aqueous solution in comparison with (i) $\mathrm{CTAB} /$ cyclohexane/1-butanol/water microemulsions with $20 \%$ wt. of CTAB, $3.4 \%$ wt. of cyclohexane and different 1-butanol/water (\% wt./\%wt.) content: $\mathrm{m}_{\mathrm{a}}=17 / 59.6, \mathrm{~m}_{\mathrm{b}}=37 / 39.6$, $\mathrm{m}_{\mathrm{c}}=57 / 19.6$, and $\mathrm{m}_{\mathrm{d}}=73 / 3.6$ and (ii) CTAB/ 1-butanol/ water reverse micelles with $20 \%$ wt. of CTAB, and different 1-butanol/water ( $\%$ wt. $/ \%$ wt. $)$ content: $r_{a}=7 / 73, r_{b}=27 / 53, r_{c}=47 / 33, r_{d}=67 / 13$.

\section{Physical properties of CTAB/1-butanol/cyclohexane/water system}

\section{Specific conductance}

Fig. 3 shows specific conductivities of CTAB/1-butanol/cyclohexane/water microemulsion and $\mathrm{CTAB} / 1$-butanol/water reverse micelle systems against 1-butanol content. It is interesting to note that although the concentration of CTAB remains constant for the microemulsions and reverse micelles, the specific conductance decreases with increasing 1-butanol content indicating a decrease in the number of conducting species in the system. The degree of ionization of the micellar headgroups was greatly influenced in the presence of 1-butanol. At higher 1-butanol content, reverse micelles were formed and the orientation of the surfactant species also changes. The cores of the reverse micelles were comprised of the hydrophilic trimethylammonium ion and the counterion $\mathrm{Br}^{-}$is less easily dissociated. This causes a significant decrease in the degree of ionization and lowers the specific conductivity with increasing 1-butanol content. The degree of ionization varies depending on the nature of the solvent, e.g. the specific conductance of $20 \%$ wt. of CTAB aqueous solution was $14.4 \times 10^{-3} \mathrm{Scm}^{-1}$, while the specific conductance of $20 \%$ wt. of CTAB in 1-butanol was $1.5 \times 10^{-3} \mathrm{Scm}^{-1}$ at $25^{\circ} \mathrm{C}$. 


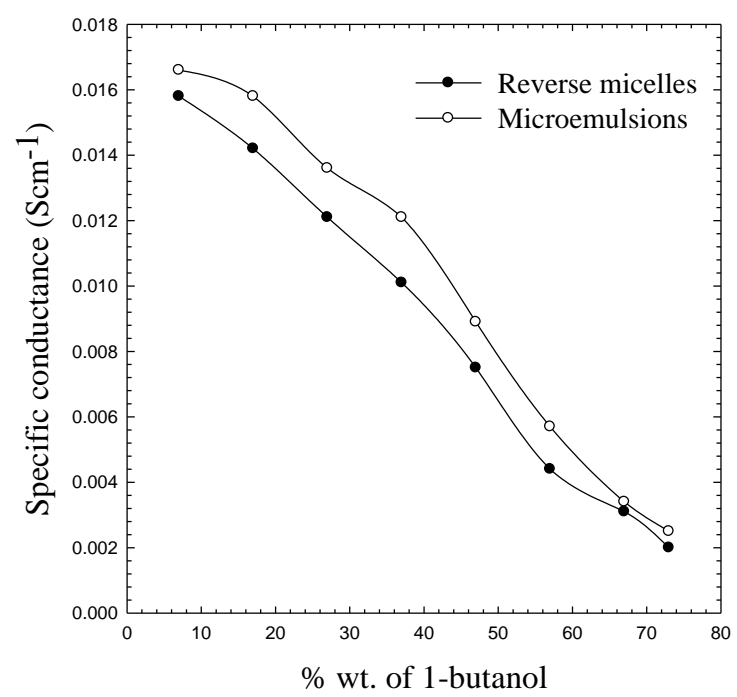

Fig. 3. Specific conductances of microemulsions ( $3.4 \%$ wt. cyclohexane) and reverse micelles ( $0 \%$ wt. cyclohexane).

\section{Density}

Fig. 4 shows densities of $\mathrm{CTAB} / 1$-butanol/cyclohexane/water microemulsion and $\mathrm{CTAB} / 1$-butanol/water reverse micelle systems. The densities of the microemulsions and reverse micelles decreased with increase in 1-butanol content. The density of 1- butanol $\left(0.8089 \mathrm{gcm}^{-3}\right.$ at $\left.25^{\circ} \mathrm{C}\right)$ is less than that of water $\left(0.9940 \mathrm{gcm}^{-3}\right.$ at $\left.25^{\circ} \mathrm{C}\right)$. The addition of $\mathrm{CTAB}$ in water or 1-butanol raised the corresponding density values. For example, when $20 \%$ wt. of CTAB was added to water, the density was found to be $0.9969 \mathrm{gcm}^{-3}$ at $25{ }^{\circ} \mathrm{C}$. Similarly when $20 \%$ wt. of CTAB was added to 1-butanol, the density was $0.8472 \mathrm{gcm}^{-3}$ at $25{ }^{\circ} \mathrm{C}$. In the $\mathrm{CTAB} / 1$-butanol/cyclohexane/water microemulsions and $\mathrm{CTAB} / 1$ butanol/water reverse micelle systems, a transition from micellar phase to reverse micelle was apparent. The low-density value of CTAB in 1-butanol solution was also reflected in the low-density values of reverse micelles. Since at high 1-butanol content, the number of reverse micellar aggregates was much higher than that of micelles, the apparent density value was found to decrease upon addition of 1-butanol. 


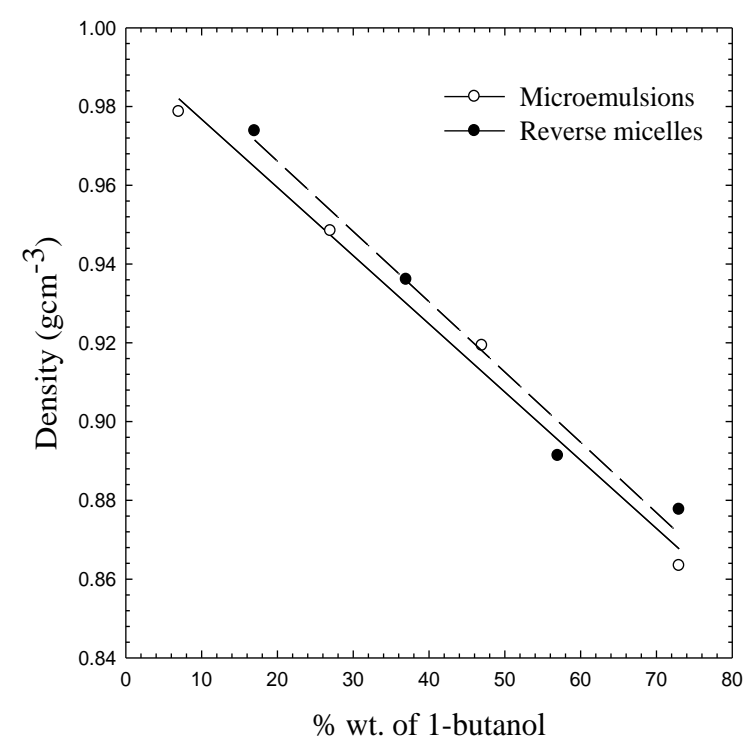

Fig. 4. Densities of microemulsions (3.4\% wt. cyclohexane) and reverse micelles (0\% wt. cyclohexane).

\section{Thermodynamic stability}

The CTAB/1-butanol/water reverse micelles and CTAB/1-butanol/cyclohexane/water microemulsions in this study were very stable for a longer period and the stability was retained upon addition of some foreign materials, which are likely to decrease the stability of microemulsions. To check the stability of microemulsions of CTAB, we have added a large amount of $\mathrm{NH}_{4} \mathrm{Cl}$ or $\mathrm{NaBr}$ and allowed to settle for several days. No change in transparency could be detected. So, addition of excess counterions or their analogues does not affect the stability of CTAB microemulsions.

Kinetics of the alkaline hydrolysis of $\mathrm{CV}$

Hydrolysis in aqueous solution and in the presence of CTAB

The alkaline hydrolysis of $\mathrm{CV}^{+}$takes place according to, $\mathrm{CV}^{+}+\mathrm{OH}^{-} \leftrightarrows \mathrm{CVOH}$; where, $\mathrm{CVOH}$ is the colorless carbinol form of the dye. In all cases the hydrolysis was carried out using a large excess of $\mathrm{NaOH}$ with respect to the substrate $\left[\mathrm{CV}^{+}\right]$, such that the reaction obeyed the pseudo-first order rate equation, -d/dt $\left[\mathrm{CV}^{+}\right]=k_{\mathrm{w}}\left[\mathrm{CV}^{+}\right]\left[\mathrm{OH}^{-}\right]=$ $k^{\prime}\left[\mathrm{CV}^{+}\right]$; where $k^{\prime}\left(=k_{\mathrm{w}}\left[\mathrm{OH}^{-}\right]\right)$is the pseudo-first order rate constant and $k_{\mathrm{w}}$ is the second order rate constant. Assuming absorbance at $592 \mathrm{~nm}$ of the reaction mixture to be due to $\mathrm{CV}^{+}$only, we obtain, $\ln \left(\mathrm{A}_{0} / \mathrm{A}\right)=k^{\prime} t$; here, $\mathrm{A}_{0}$ is the initial absorbance and $\mathrm{A}$ is the absorbance at any time, $t$. The values of $k^{\prime}$ were evaluated from a least square fit of the plot of $\ln \left(\mathrm{A}_{0} / \mathrm{A}\right)$ vs. $t$. The $k_{\mathrm{w}}$ for the title reaction in water has been evaluated from the plot of $k^{\prime}$ vs. $\left[\mathrm{OH}^{-}\right]$and was found to be $0.234 \mathrm{M}^{-1} \mathrm{~s}^{-1}$, which agrees with literature ${ }^{13,43}$. 
The $k^{\prime}$ vs. [CTAB] profile for the alkaline hydrolysis of $\mathrm{CV}$ in the presence of CTAB shows interesting behavior ${ }^{11}$. At $0.01 \mathrm{M}$ concentration of $\left[\mathrm{OH}^{-}\right]$, the rate constant increases with increase in $[\mathrm{CTAB}]$. After the CMC $\left(8.75 \times 10^{-4} \mathrm{M}\right)$, a pronounced sharp increase in the rate constant is observed and the rate is enhanced up to more than 10-fold in micellar solutions of CTAB. These results clearly indicate that it is the micelle, which is responsible for enhancing the rate of the hydrolysis of $\mathrm{CV} . \mathrm{CV}^{+}$is easily solubilized into the hydrophobic core of micelle in aqueous solution and the concentration of $\mathrm{CV}^{+}$is much higher in the micelle core compared to that in the bulk. The observed rate constant is the average rate constant of the hydrolysis which occur in the two different environments (hydrolysis outside the micelle core and inside the micelle core). But enhancement of the concentration in the micellar pseudo phase as well as change in reactivity brings about significant increase in the reaction rate. The $k^{\prime}$ vs. [CTAB] plot reaches a maximum at ca. $0.01 \mathrm{M}$, after which the rate constant has been found to decrease gradually with increase in $[\mathrm{CTAB}]$. As the concentration of CTAB is further increased, the electrostatic repulsion between the micellar head groups and positively charged $\mathrm{CV}$ increases discouraging further solubilization of $\mathrm{CV}^{+}$in the micelle core. It is the reduction of the concentration of $\mathrm{CV}^{+}$in the micelle core that causes a gradual decrease in the rate of the hydrolysis in the system.

In the kinetic runs for reverse micelles and microemulsions, $20 \%$ wt. of CTAB was used, which corresponds to ca. $0.5 \mathrm{M}$. The kinetics of the alkaline hydrolysis of $\mathrm{CV}$ has, therefore, been also studied in aqueous solution using $0.5 \mathrm{M}$ of CTAB concentration and the result has been compared with that in aqueous solution without added surfactant. The $k^{\prime}$ in $0.5 \mathrm{M}$ CTAB solution was lower than the corresponding value without surfactant in aqueous solution under identical experimental conditions. This is indicative of strong repulsive forces between the micellar head groups and $\mathrm{CV}^{+}$, which ultimately causes inhibition. The significant change in the rate constant may also be ascribed to a change in solubilization originating from the change in micellar structure: from sphere to rod at extremely high concentrations.

\section{Hydrolysis in 1-butanol}

The $k^{\prime}$ for the reaction in aqueous solution shows a strong dependence on the dielectric constant of the medium ${ }^{40}$. 1-butanol has lower dielectric constant $\left(18.3\right.$ at $\left.25{ }^{\circ} \mathrm{C}\right)$ compared to water $\left(80\right.$ at $\left.25^{\circ} \mathrm{C}\right)$. The $k^{\prime}$ of the alkaline hydrolysis of $\mathrm{CV}$ with $\left[\mathrm{OH}^{-}\right]=7.4$ $\times 10^{-3} \mathrm{M}$ in aqueous solution is $1.73 \times 10^{-3} \mathrm{~s}^{-1}$ ) and in 1 -butanol is $17.70 \times 10^{-3} \mathrm{~s}^{-1}$. This indicates that a solvent having lower dielectric constant, favors the hydrolysis reaction of $\mathrm{CV}$ compared to that with a high value ${ }^{40}$. The $k^{\prime}$ value for the title reaction under identical experimental conditions using water with $20 \%$ wt. of CTAB was also found to be much lower $\left(1.17 \times 10^{-3} \mathrm{~s}^{-1}\right)$ than that in 1-butanol with $20 \%$ wt. of CTAB $\left(8.79 \times 10^{-3} \mathrm{~s}^{-1}\right)$.

\section{Hydrolysis in reverse micelles and microemulsions of CTAB}

Fig. 5 represents the $k^{\prime}$ vs. \% wt. of 1-butanol for CTAB/1-butanol/water reverse micelles 
and $\mathrm{CTAB} / 1$-butanol/cyclohexane/water microemulsions. As the content of 1-butanol in reverse micelles and microemulsion increases, the $k^{\prime}$ decreases first and then gradually increases; however, at higher 1-butanol content (>50\% wt.) a sharp increase is apparent. The rate constant attains value much higher than the corresponding value in aqueous solution under identical experimental conditions. This is a clear indication of catalysis of the title reaction by microemulsions and reverse micelles.

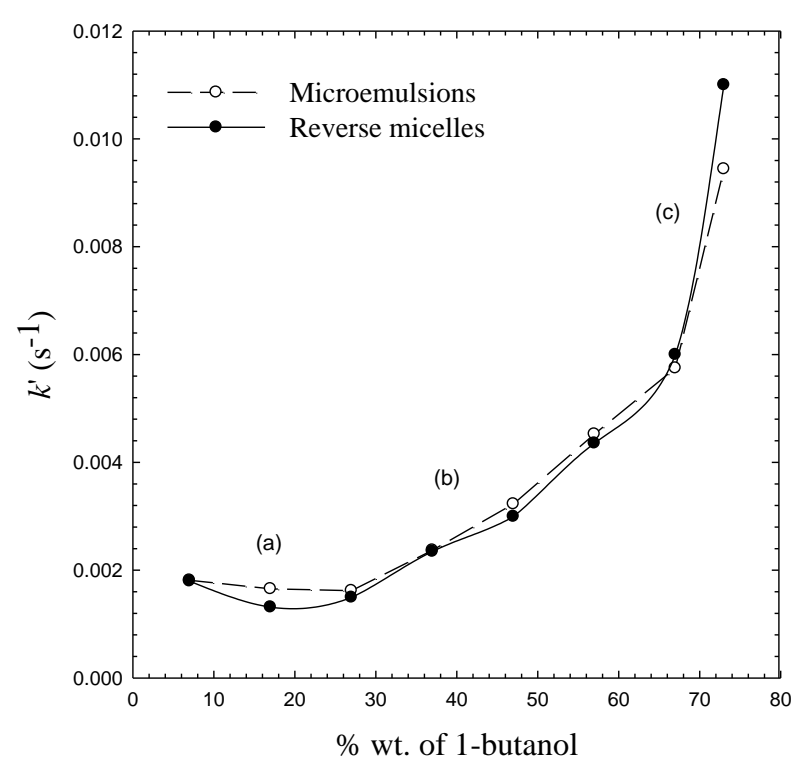

Fig. 5. $k^{\prime}$ vs. $\%$ wt. of 1-butanol for microemulsions ( $3.4 \%$ wt. cyclohexane) and reverse micelles (0\% wt. cyclohexane).

It is not surprising that microemulsions and reverse micelles affect chemical reaction rates. It is, however, difficult to give a quantitative explanation for the kinetic data since different factors influence micellar catalysis or inhibition. Since 1-butanol is a very important component of the microemulsions and reverse micelles, we studied the influence of 1-butanol on the title reaction in surfactant solutions to understand the effects of the micellar systems on chemical reactivity.

The kinetic rate constants (Fig. 5) may be further analyzed to have a deeper understanding of the mechanism of catalysis by microemulsions and reverse micelles. In part ' $a$ ' of the Fig. 5, there is a decrease in rate constant with the 1-butanol content and it corresponds to the region of direct $\mathrm{CTAB} / 1$-butanol micelle in water where 1-butanol incorporation into the CTAB micelles inhibit the reaction ${ }^{26}$. Part ' $c$ ' of Fig. 5, corresponds to the reaction in reverse micelle where a decrease in the water content is related to a structured water phase with lower dielectric constant that produces an increase in the 
reaction rate ${ }^{21}$. Part ' $b$ ' of the Fig. 5 may well correspond to a transition phase from the direct micelles in water to reverse micelles in 1-butanol. In this region the water is not structured and the rate constant has nearly the same value as the second order rate constant for the reaction in water ${ }^{43}, k=0.234 \mathrm{M}^{-1} \mathrm{~s}^{-1}$.

Correlations of physical properties of reverse micelles and microemulsions with kinetic results

As the content of 1-butanol increases in the reverse micelles and microemulsions, the specific conductance as well as the density decrease. The change in physical properties also causes change in reaction environment, which is changed from a micelle-rich low 1butanol condition ( $\mathrm{o} / \mathrm{w}$ microemulsion) to a reverse micelle-rich high 1-butanol condition (w/o microemulsion). Thus, the rate for the alkaline hydrolysis of $\mathrm{CV}$ has been found to be influenced by specific conductivity and density of CTAB/cyclohexane/1-butanol/water microemulsion and CTAB/1-butanol/water reverse micelle system.

It is the micelle, which is responsible for enhancing the rate of the alkaline hydrolysis of $\mathrm{CV}$. CV is easily solubilized into the hydrophobic core of micelle in aqueous solution and the concentration of $\mathrm{CV}^{+}$is much higher in the micelle core compared to that in the bulk. The observed rate constant is the average rate constant of the hydrolysis which occurs in the two different environments (hydrolysis outside the micelle core and inside the micelle core). But enhancement of the concentration in the micellar pseudo phase as well as change in reactivity brings about significant increase in the reaction rate ${ }^{44}$. Incorporation of 1-butanol to cationic CTAB micelles displaces the substrate from the micellar into the aqueous phase ${ }^{19}$. Also as the content of reverse micelle is increased in the w/o microemulsions, the orientation of the surfactant species entirely changes bringing about a change in the reaction mechanism.

\section{Conclusion}

The alkaline hydrolysis of $\mathrm{CV}$ is catalyzed by micelles, reverse micelles and microemulsions of CTAB. Above the CMC of CTAB, the reaction is catalyzed by the micelles of $\mathrm{CTAB}$ and the rate of the reaction is significantly enhanced. However, the rate of the reaction at extremely high concentrations of $\mathrm{CTAB}$ has been found to decrease due to the increased electrostatic repulsion between the micellar head groups and positively charged $\mathrm{CV}$, which discourages further solubilization of $\mathrm{CV}$ in the micelle core. It is the reduction of the concentration of $\mathrm{CV}^{+}$in the micelle core, which causes an apparent decrease in the reaction rate at very high $\mathrm{CTAB}$ concentrations. The $k^{\prime}$ vs. $\%$ wt. of 1-butanol profiles for reverse micelles and microemulsions of CTAB showed an initial decrease in the $k^{\prime}$ followed by a gradual increase with increasing 1-butanol content, which may be ascribed to the increased amount of reverse micelles of CTAB in the microemulsions and reverse micelles. Microemulsions and reverse micelles can thus influence the rate of the reaction by formation of micelles in water phase and reverse 
micelles in oil phase.

\section{Acknowledgement}

The authors gratefully acknowledge financial support for a sub-project (CP-231) from the Higher Education Quality Enhancement Project of the University Grants Commission of Bangladesh financed by World Bank and the Government of Bangladesh.

\section{References}

1. J. H. Fendler and E. J. Fendler; "Catalysis in Micellar and Macromolecular Systems", Academic Press, New York, 1975.

2. M. N. Khan; "Micellar Catalysis (Surfactant Series)”, CRC Press, 2006.

3. S. Gabriela, M. Donia, I. Alina and B. Adrina, Rev. Roumaine Chim., 2006, 50, 767.

4. Y. S. Simanenko, A. F. Popov, T. M. Prokopeva, E. A. Karpichev, I. A. Belousova and V. A. Savelova, J. Theo. Exp. Chem., 2002, 38, 242.

5. C. O. R. Yagui and A. P. Junior, J. Pharm. Sci., 2005, 8, 147.

6. F. Monica and V. Carmen, Eur. J. Pharm. Sci., 2007, 31, 211.

7. M. N. Khan, P. C. Gleen and A. Zainudin, Ind. J. Chem., 1996, 35, 758.

8. M. E. Moro, J. N. Fertrell, M. M. Velazquez and L. J. Rodriguez, J. Pharm. Sci., 1991, 80, 459.

9. L. Mukherjee, N. Mitra, P.K. Bhattacharya and S. P. Moulick, Langmuir, 1995, 11, 2866.

10. R.Y. Talman, S. Gokturkand and M. Tuncay, Colloids Surfs., 2005, 270, 72.

11. J. Datta, A. Bhattiacharya and K. Kundu, Ind. J. Chem., 1988, 27, 115.

12. C. Dolect and E. Rodenas, Colloids Surfs. A: Physicochem. Eng. Asp., 1993, 75, 392.

13. E. F. J. Duynstee and E. Grunwald, J. Am. Chem. Soc., 1959, 81, 4540.

14. M. Isabel, M. L. Sierra, M. Valiente and E. Rodenas, J. Chem. Soc., 1996, 92, 59.

15. Z. Yuanqin, L. Xiaoyan, L. Jing and Z. Xiancheng, J. Disp. Sci. Tech., 2002, 23, 473.

16. A. R. Kabir and M. A. B. H. Susan, J. Saudi Chem. Soc., 2008, 12, 543.

17. M. L. Sierra and E. Rodenas, J. Phys. Chem. 1993, 97, 12387.

18. L. G. Río, J. R. Leis, J. C. Mejuto, A. N. Vázquez, J. P. Juste and P. R. Dafonte, Langmuir, 2004, 20, 606.

19. M. Valiente and E. Rodenas, Langmuir, 1990, 6, 775.

20. J. R. Leis, J. C. Mejuto and M. E. Pena, Langmuir, 1993, 9, 889.

21. M. Valiente and E. Rodenas, J. Phys. Chem., 1991, 95, 3368.

22. L. Mukhopadhyay, N. Mitra, P. K. Bhattacharya and S. P. Moulcik J. Colloid Interface Sci., 1997, 186, 1.

23. M. Valiente, E. Rodenas and E. P. Benito, Tenside Surf. Det., 1994, 31,168.

24. C. Izquierdo, J. Casado, A. Rodriguez and M. L. Moya, Int. J. Chem. Kinet. 1992, 24, 19. 
25. Y. Ikushima, Z. Shervani, N. Saito and M. Arai, J. Colloid Interface Sci., 1997,191,177.

26. M. Valiente and E. Rodenas, J. Colloid Interface Sci., 1989, 127, 522.

27. M. Valiente and E. Rodenas, J. Colloid Interface Sci., 1990, 138, 299.

28. M. Valientie and E. Rodenas, J. Am. Chem. Soc., 1990, 6, 775.

29. M. Häger, F. Currie and K. Holmberg, Colloids Surfs., 2004, 250,163.

30. K. K. Ghosh and M. L. Satnami, Colloids Surfs., 2006, 274, 125.

31. O. Noritaka, S. Akira, N. Ryotaro, and Y. Tsuyoshi, J. Japan Oil Chem. Soc., 2000, 49,817.

32. C. A. Bunton and F. D. Buzzaccarin, J. Phys. Chem., 1981, 85, 3142.

33. A. B. Mirgorodskaya and L. A. Kudryavtseva, Russ. J. Gen. Chem., 2002, 72, 1261.

34. Y. Miyake, T. Owari, K. Matsuura and M. Teramoto, J. Chem. Soc., Faraday Trans., 1994, 90, 979.

35. Y. Miyake, T. Owari, F. Ishiga and M. Teramoto, J. Chem. Soc., Faraday Trans., 1993, 89, 1993.

36. H. Jingcheng, J. Disper. Sci. Technol., 2000, 21, 19.

37. F. Tafesse and K. Eguzozie, Ecotoxicol. Environ. Saf., 2009, 72, 954.

38. H. Xiaojuan, A. Xueqin, C. Zhiyun and S. Weiguo, Chin. Sci. Bull., 2004, 49, 317.

39. Z. Y. Chen, J. H. Zhao, W. He, X. Qinan and W. G. Shen, Int. J. Chem. Kinet., 2008, 40, 294.

40. M. Valientie and E. Rodenas, Colloid Polym. Sci., 1993, 271, 494.

41. P. Ekwall, L. Mandell and K. Fontell, J. Colloid Interface Sci., 1969, 29, 639.

42. G. N. Lewis, T. T. Magel and D. Lipkin, J. Am. Chem. Soc., 1942, 64, 1774.

43. C. D. Ritchie, D. J. Wright, D.S. Huang and A. A. Kamego, J. Am. Chem. Soc., 1975, 97, 1163.

44. D. Meyers; "Surfaces, Interfaces and Colloids", VCH Publishers, Inc., New York, 1991. 